\title{
Disability, space and sexuality: access to family planning services ${ }^{1}$
}

\author{
Paul Anderson ${ }^{\mathrm{a}}$, Rob Kitchin ${ }^{\mathrm{b}, *}$ \\ ${ }^{a}$ Family Planning Association, University Street, Belfast BT7 1HP, Northern Ireland, UK \\ ${ }^{\mathrm{b}}$ Department of Geography, National University of Ireland, Maynooth, County Kildare, Ireland
}

\begin{abstract}
In this paper we examine, from a social perspective, access to family planning clinics for disabled people. We argue that disabled people are commonly understood to be either asexual, uninterested in sex or unable to take part in sexual activity, or sexual 'monsters' unable to control their sexual drives and feelings. These understandings are reproduced through the use of cultural representations and myths, and are evidenced in the planning and design of family planning clinics and the information and services they provide. To illustrate our arguments we present the findings of a short questionnaire survey of all family planning clinics in Northern Ireland. Physical access to these clinics was partial, and access to information and services were extremely limited. These results indicate that disabled people are not expected to be using the services (consultation, treatment, information) that family planning clinics provide. As such, family planning clinics in Northern Ireland represent a landscape of exclusion, denying disabled people access to services and reproducing cultural ideologies concerning disability and sexuality. (C) 2000 Elsevier Science Ltd. All rights reserved.
\end{abstract}

Keywords: Family planning; Disability; Sexuality; Cultural ideologies; Social exclusion

\section{Introduction}

[D]isabled people are people, and people are sexual. Much of our sense of personhood comes from our

\footnotetext{
* Corresponding author. Tel.: $+353+1+708+3372$; fax: $+353+1+708+3573$.

E-mail addresses: paul@carrowreagh.freeserve.co.uk (P. Anderson), Rob.Kitchin@may.ie (R. Kitchin).

${ }^{1}$ The research reported here was funded by the Royal Irish Academy under the title 'Developing a Participatory Action Research Approach: Access, Accessibility and Measuring Disabling Environments'.
}

ability to play a sexual role. ...[D]isabled [people] share with the rest of us the misfortune of living in a society that has traditionally avoided and censured sex, but this hits...disabled [people] harder than others. Moreover, virtually nobody is too disabled to derive some satisfaction and personal reinforcement from sex — with a partner if possible, alone if necessary (Comfort, 1975; our emphasis)

...the disability rights movement has never addressed sexuality as a key political issue, though many of us find sexuality to be the area of our great oppression. We may well be more concerned with being loved and finding sexual fulfilment than getting on a bus (Waxman \& Finger, 1991. p. 1). 
There can be little doubt that disabled people ${ }^{2}$ need access to services that provide advice and health care relating to sexual issues. Despite common stereotyping to the contrary, and attempts to treat disabled people as though sexuality and self-image do not exist (Monga \& Lefebrve, 1995), disabled people are sexual beings. Like non-disabled people they experience feelings of desire and love, seek sexual gratification, and many hope to sustain long-term sexual relationships and start/care for families. Like non-disabled people they can also be the victims of sexual abuse. In fact, it is widely reported that disabled people are more likely to be sexually abused (for overviews see Fegan, Rauch \& McCarthy, 1993; Watson-Armstrong, O'Rourke \& Schatzlein, 1994; Nosek, 1995). This given, it is only recently that researchers and practioners have started to consider access to sex education, sexual health and family planning. Most of this work has been from a medical perspective, concentrating on the levels of support needed from health care professionals and the form that this support should take.

In this paper, we examine from a social perspective the provision of family planning services to disabled people. This perspective recognises that disabled people are a heterogeneous population, and that the majority of daily difficulties faced by disabled people are caused by society failing to accept disabled people for who they are and failing to provide adequate services. We focus our attention on the ways in which society reproduces myths that disabled people lack sexual desire, are unable to partake in sexual activity, and are unable to engage in long-term mutually satisfying sexual relationships (DeLoach, 1994), and how these myths are manifested in access to family planning clinics both in relation to how they are designed and built, and in the levels of services they offer to disabled people.

\section{Disability and sexuality}

It is now commonly recognised that disabled people generally occupy marginal positions in society (see Oliver, 1996). In recent years a number of scholars have started to deconstruct the ways in which the marginal position of socially excluded groups, including disabled people, is sustained and reproduced. Central in this project has been the examination of the ways in which groups are positioned in relation to each other and how these positions are maintained through power relations. One key practice in the reproduction of pos-

\footnotetext{
${ }^{2}$ We broadly define disabled people, as discussed in this paper, as those people who have physical/sensory impairments, chronic pain, developmental/learning impairments or mental illness.
}

itions of power are cultural ideologies. Cultural ideologies work to legitimate material and discursive discriminatory practices, such as exclusion from family planning clinics, sex education and sexual health, by suggesting that current social relations are commonsense and natural (rather than constructed and negotiable); that the lifestyles, practices, minds and bodies of non-disabled people are the 'norm' and those of disabled people are deviant and undesirable. These cultural ideologies are sustained through the use of cultural representations - the portrayal of disabled people and the conceptualisation of disability — which frame and legitimate how society views and treats disabled people.

In modern western societies, disabled people are commonly portrayed as abnormal, child-like, 'damaged goods', 'freaks of nature', unattractive, dependent, in need of protection, a danger unto themselves, an object of pity, unproductive, anti-social, and tainted by disease/ill-health. These representations have been fed in the main by ideas of deviancy from the norm and supposed inferiority and danger. Labels such as 'invalid', 'cripple', 'spastic', 'handicapped' and 'retarded' all imply both a functional loss and a lack of worth and perpetuate and legitimate offensive responses by nondisabled people including horror, fear, anxiety, hostility, distrust, pity, over-protection and patronising behaviour (Barton, 1996, p. 8). In relation to disability and sexuality, the common cultural representations are ones of asexuality, with disabled people uninterested in sex or unable to take part in sexual activity, or as sexual 'monsters', unable to control their sexual drives and feelings. As Lamb and Layzell (1994, p. 21) state:

There is an unspoken taboo about relationships and disabled people. Disabled people's sexual and emotional needs are rarely included in any discussion or representation in everyday life, whether this is in the papers and magazines we read, or the movies we watch. This reinforces the public's attitudes and expectations towards disabled people as seeing them as 'sick and sexless' rather than participating in full sexual and family relationships.

Cultural representations of disabled people as 'sick and sexless' is supported and sustained by a set of myths. Myths in relation to disability and sexuality include disabled people being asexual, that is lacking a biological sex drive, being unable to partake in sexual activity, and that disabled people (particularly those with a developmental/intellectual disability) lack the requisite social judgement to behave sexually in a socially responsible manner (DeLoach, 1994). For example, a number of myths have been used to reinforce and reproduce heterosexual and patriarchal ideologies in relation to disability and gender roles. 
Women's identity in western society is often defined around themes such as reproduction, home-making, and body-image (Schlesinger, 1996; Tilley, 1996). Disability disrupts these themes. O'Toole and Bregante (1992, p. 166) list a number of common myths relating to disabled women and sexuality: disabled women are asexual; disabled women who are not married do not have sex (and those who are married did so before they became disabled); disabled women cannot be mothers; if a mother becomes disabled, her children are not getting a 'real' mother; in relationships, the non-disabled person runs the relationship; disabled women should be grateful for a sexual relationship; disabled women are too fragile for vigorous sexual activity; all disabled women are heterosexual. Women with disabilities thus have a poor body-image and are unable to fulfil their role as women. In addition, they are economically unproductive and thus a burden to society (DeLoach, 1994; Nosek, 1995). A consequence of these myths is that, as Tilley (1996) reports, disabled women are less likely to have received sex education classes and basic sexual health such as Pap smears and internal and breast cancer examinations. Moreover, many intellectually disabled women have been forcibly sterilised. In contrast, male identity is often defined around sexual prowess, fitness and work. Again disability disrupts these themes and undermines disabled men's sense of masculinity. Several researchers have noted that many disabled people suffer from low selfesteem and feelings of inferiority due to their disability and body image (e.g. Tan and Bostick, 1995; Schlesinger, 1996).

These myths help to sustain, and provide legitimacy for, current socio-sexual relations - reinforcing them for non-disabled people and internalising them within disabled people. As such, DeLoach (1994) argues that these ideologies lead to self-perpetuating and reproducing cycle: (1) non-disabled people's attitudes towards disabled people are primarily negative; (2) feelings associated with these attitudes range from hostility and aversion to sympathy and pity; (3) behaviours associated with these attitudes lead to the isolation or marginalisation of disabled people; (4) the attitudes and behaviour of disabled people are strongly and negatively influenced by non-disabled attitudes and behaviours. This has led Waxman and Finger (1991) to conclude that in western society '(1) it is almost illegal to be severely disabled and married [indeed, in some countries it has been/is illegal for disabled people to be married (Fegan et al., 1993; Tilley, 1996)], (2) disabled people are denied sexual and reproductive freedom and the liberty to establish families in forms that they choose, (3) there is no other group in [western society] that faces the sorts of sexual and reproductive restrictions that disabled people do, (4) disabled people are frequently prevented from marrying, bearing or rearing children, learning about sexuality, having sexual relations, and obtaining sexual literature'. The currency of these myths feed in part to the breakdown of marriages and relationships when one partner becomes disabled or suffers chronic pain. For example, Pitzele (1995) reports that $75 \%$ of women who became disabled were later divorced and Badeau (1995) reports that healthy partners can place a strain on relationships through a tendency to mother, infantilize and overprotect or through behaviour changes due to fear of hurting their partner or catching a condition.

The effects of this maintenance of hegemony is even more pronounced for disabled people who are gay, lesbian or bisexual, and for those over the age of fifty, as ableist-based sexual oppression intersect with aspects of homophobia and ageism. O'Toole and Bregante (1992) and McAllen and Ditillo (1994) report that lesbians with disabilities experience particular circumstances. Not only do they have a sexual identity, but it is one which is considered by many to be deviant. The effect of this is often externally-situated social isolation (from non-disabled people) coupled with internalised isolation (homophobic disabled people). This has led to a situation in which disabled lesbians are largely invisible (see Butler, 1999). There is virtually no information available for disabled lesbians and sexual health care can be affected by negatively positioned health care workers (e.g. O’Toole \& Bregante, 1992, detail cases where disabled, lesbian patients were abused by nurses). Moreover, O'Toole and Bregante (1992) report that partners are denied the same rights that would expect in a straight relationship, and are often positioned as somebody 'taking advantage' or being 'a corrupting influence' by family and health care workers.

In relation to age, Pitzele (1995) details that there is a common misconception that sexuality and interest dissipates rapidly over the age of fifty and that it disappears entirely amongst those who acquire a chronic illness or disability. Ghusn (1995) reports that the sexuality of institutionalised older people is often ignored or misinterpreted and is nearly always seen as inappropriate or deviant. Badeau (1995) suggests that older disabled people are effectively neutralised sexually through the desire to fit into social norms and the fear of being reprimanded and stigmatised.

A consequence of the reproduction of ableist ideologies is that some disabled people live in an overprotective environment that inhibits ordinary and social exploration (DeLoach, 1994; Tan \& Bostik, 1995). Some parents of disabled children (regardless of impairment) can mollycoddle their children, denying them the time, space and opportunity to develop and explore their sexuality, fearful that their children will be unable to establish and maintain a relationship, leading to hurt and resentment (Nelson, 1995). In 
other cases, efforts are directed at discouraging sexual expression for fear of opening Pandora's box (DeLoach, 1994). As such, sources of learning about sexuality such as playing with peers, joining clubs, falling in love, experimenting, peeping and reading pornography are denied (Rousso, 1982).

Similarly, the sexuality of institutionalised disabled people is repressed and overt sexual expressions punished in many institutional settings, primarily due to staff conceptions of 'appropriate' sexuality (Wolfe, 1997). This is particularly the case for people with developmental/intellectual disabilities. Indeed, McCabe, Cummins and Reid (1994) report that the majority of this group themselves believed that someone else decides about the level of their sexual experience and their levels of sexual knowledge, and understandings of consent were poor and naive, potentially leaving them open to abuse - particularly if deinstitutionalised into the community (Szollos \& McCabe, 1995). Fegan et al. (1993) suggest that people with developmental/intellectual disabilities are vulnerable because they are less likely to resist, less likely to report, and if they do report less likely to be believed. They are, therefore, a group in particular need of sex education. This suppression of disabled peoples' sexuality in part is due the conception that it may encourage unacceptable behaviour, although there is little evidence that rates of sexual offence are higher for intellectually disabled people (McCabe et al., 1994). People with intellectual disability are either viewed by staff as asexual or oversexed and lacking control, with men seen as potentially sexually aggressive and women promiscuous (Clements, Clare \& Ezelle, 1995; Szollos \& McCabe, 1995). Szollos and McCabe (1995) detail a number of studies conducted in North America that revealed that staff enforced rules concerning physical contact and sexual behaviour through segregation and supervision and that many felt that sex education and conversations about sex should not be permitted. Here, staff subscribe to a view that sex education for disabled people should consist of control or elimination of sexual interest and expression through sterilisation, restricted privacy and controlling behaviour (Fegan et al., 1993). A consequence of this overprotection and 'mothering' is that institutionalised disabled people, regardless of impairment, are socialised into a disabled, asexual role, with poor body-image and low self-esteem (Rousso, 1982).

It is inevitable then that cultural ideologies work at all levels of society, including health and social services. This leads to a situation where the level and types of services health care professionals provide is often inadequate in relation to the needs and desires of disabled people. That is, there is an expectation within the health services, as with society in general, that disabled people are asexual: uninterested in, and unable to perform, sex or in the case of children and people with developmental disabilities that they need to be denied the opportunity to explore their sexuality. For example, Wolfe (1997) surveyed 98 special education teachers and administrators in Virginia about attitudes towards disabled people (specifically those with moderate or severe disabilities) and sexuality. The majority felt that sexual relations were inappropriate for disabled people. Moreover, the majority of respondents felt that disabled people should not have children and should be sterilised. Similar attitudes exist in other service providers (e.g. see special issue of Journal of Applied Rehabilitation Counseling). Many of the disabled people we have talked to over the past year have confirmed that these attitudes are common. For example, one female, life-long wheelchair user described her frustration that people automatically assumed that she was a spinster and not sexually active - her husband was her brother and her children her nephews. Moreover, she felt that society and health care providers viewed her as irresponsible for having children.

\section{Socio-spatial constructions of disability and sexuality}

On the subject of families, I stopped going to the family planning clinic because I felt so out of place. The waiting room was always full of 'young girls', and I felt conspicuous with my sticks (I couldn't go in my wheelchair because the ramp was too steep!). I usually feel strong as a disabled person, but hospitals and health centres have an adverse effect. (Caroline in Shakespeare, Gillespie-Sellis \& Davies, 1996, p. 15, our emphases).

Geographers and others have for a number of years been examining the ways in which space is organised to reproduce dominant, cultural ideologies and exclude certain social groupings; to map out landscapes of exclusion (see Cresswell, 1996; Jackson, 1989; Sibley, 1995). Part of this project has involved identifying the ways in which disabled people are excluded and marginalised in society through examining how society is spatially organised, environments are designed, and decoding the messages inscribed within certain spaces (see Butler \& Parr, 1999; Gleeson, 1999; Imrie, 1996; Kitchin, 1998, for overviews).

In the rest of this paper we adopt a social model perspective to examine how cultural ideologies are reproduced and reflected in how family planning clinics are designed and built, and in the levels and types of services they offer to disabled people. In part, we do this through an examination of the ways in which the built landscape is socio-spatially constructed. Here it is 
recognised that buildings and services are designed and produced by people and they are therefore social constructions, imbued with the values of the designers geographies are created through the interplay of many agencies both institutional and individual. As creations, there is nothing 'natural' about inaccessible landscapes.

The urban landscape is replete with examples of spaces that explicitly segregate disabled people into differing spatial spheres: asylums, segregated schools, employment training centres and day-care units; and implicitly marginalise disabled people in public and private space: inaccessible toilets, restricted seating in theatres and cinemas, places that use steps but have no ramp, cash machines that are placed too high for wheelchair users, places linked by inaccessible public transport. Many urban spaces are inaccessible or difficult to negotiate for many disabled people because they have not been designed and built with them in mind (see Imrie, 1996; Kitchin, 1998). The message generally conveyed to disabled people by segregated and marginal spaces is clear — that they are 'out of place':

Good inclusive design will send positive messages to disabled people, messages which tell them: 'you are important'; 'we want you here'; and 'welcome'.

...if the way that disabled people are expected to get into a building is round the back, past the bins and through the kitchens, what does that message communicate? How will it make a disabled person feel? (Napolitano, 1995, p. 33).

The consequences of these spaces are numerous. At a fundamental level they reproduce the current social relations of disabled people as 'out of place' in the public sphere. They restrict access to employment, housing, leisure and recreational activities. In other ways they feed directly into issues of sexuality that affect disabled people. For example, Muccigrosso (1991) reports that living in segregated, institutional and overprotective environments denies many disabled people access to formative relationships and sex education and has a number of by-products: (1) lack of knowledge, (2) overcompliance and socialized vulnerability, (3) an unrealistic view that everyone if a friend, (4) limited social opportunities, (5) low self-esteem, and (6) limited or no assertiveness.

The provision and design of family planning clinics, we would argue, needs to be analysed within a framework that deconstructs their design and is contexted in issues of social justice and citizenship. In relation to the latter point, two important themes are critical: access and dignity. Disability movements have recently been at the forefront of the struggle to define citizenship and social justice with reference to embodiment; in other words, to ensure that rights are not simply abstract concepts but can be exercised by human beings with all kinds of bodies (Kitchin \& Law, forthcoming). Activists and scholars have repeatedly argued that full participation in civic affairs - an essential element of social justice - depends on the material conditions which shape people's ability to participate (Gleeson, 1999). For disabled people, the provision of public services and the design of the built environment can be a crucial determinant of participation.

An element of access that is central to services such as family planning is dignity. Sexual health is generally regarded as an intensely private concern, with stigma attached to issues such as sexual diseases and unwanted pregnancies. A core concept of family planning then is to provide private spaces such as consultation rooms for client and service provider to talk and carry out examinations. Similarly, public toilet provision has a number of social conventions such as discreetly dealing the body's needs, away from the gaze of others, in demarcated settings with some spatial separation from other activity spaces, using facilities which meet public health standards on the disposal of human waste and control of dirt. Consequently, to be placed in a situation where you are unable to go to the toilet without breaking the social conventions which surround the act can be understood as a denial of your rights to participate in social life with dignity (Kitchin \& Law, forthcoming). In order to ensure dignity for disabled people attending family planning clinics all such private spaces should conform to social conventions to ensure dignified use of the service.

In the project reported below we sought to discover the extent to which disabled people occupy an unjust and exclusionary landscape; the extent to which they are 'out of place' in family planning clinics in Northern Ireland through an assessment of their levels of access: physical, social and informational. That is, to determine through an analysis of the socio-spatial environment the extent to which the disabled people are viewed and treated as having a sexuality and in need of sexual health care services. The work extends and entwines a number of discourses within the geographic literature concerning geographies of sexuality, geographies of disability, and geographies of health care provision/siting. In our example case of Northern Ireland, we were interested in the ways in which sexuality and disability are socio-spatially written, and how dominant ideologies manifest themselves in the provision of sexual health-care and family planning clinics. The only related work we have found are a few quotes by respondents in Shakespeare et al.'s (1996) study that highlight difficulty with access to family planning clinics in the UK, an observation by Tilley (1996) that disabled women tend not to have Pap smears largely 
due to inaccessible doctor surgeries, and an informal survey of battered women's shelters in Houston which found that $64 \%$ were inaccessible to wheelchair users (and presumably other physical and sensory impairments) (Nosek, 1995). Here, it is likely that disabled women were not even considered in the purchase and use of the shelter due to an implicit assumption that disabled women would not be in relationships, let alone abusive ones.

\section{The Northern Ireland context}

According to PPRU (1992) there are 201,000 adults in Northern Ireland with disabilities. This population is heterogeneous in terms of type of impairment (medical condition), the disability encountered (e.g. locomotion, sight, hearing), and the severity of the disability. They live in a generally ableist society, where most disabled people do not enjoy the same status, facilities and services experienced by non-disabled people. Their socio-spatial position is shaped by a moral conservatism where dominant cultural ideologies are framed by religious constructions of disability, a weak legislative framework and stereotyping in the popular media.

The churches preaching on disability has left many disabled people in marginal social positions. Hughes (1998) details that religious constructions of disability portray disabled people as deviant and 'unnatural beings', and a literal reading of the Bible portrays disabled people as abominations (see for example, Leviticus 21: 16-20). Here, the value of disabled life and the contribution to society by disabled people has been questioned by the church, and we know of at least one example where a cleric refused to marry a disabled couple on the grounds that they could not consummate the marriage through penetrative sex. Moreover, the church has heavily implicated in the eugenics movement that sought to sterilise disabled people (Park \& Radford, 1999). Many might counter that the church has also been involved in many humanitarian missions for disabled people, helping to school and house them. We would contend that these missions led to widescale institutionalisation of disabled people and their removal from, and participation in, their local community. This Imrie (1996) contends has reinforced cultural ideologies, notions of difference, and legitimated ableist attitudes and practices. The influence of the church in Northern Ireland is still probably stronger than in other parts of the UK, with a large church going population (Hickey, 1986). Moreover, many schools are church run, and there is a strong sectarian geography to education, the workplace and residential location.

Whilst religious constructions of disabled people as 'abominations' have weakened significantly in recent years, and the role of religion in general has diminished, it still plays a part in shaping social attitudes in the Province. One particular issue where the church seeks influence is in relation sexuality. In general, the church preaches on the sanctity of the family, the ethics of pro-life, and the sins of homosexuality. These values help to shape social attitudes to sexuality, and in turn help shape services and legislation that affect all members of the community including disabled people. A consequence is that Northern Ireland is the only place in the UK where abortion is still illegal, it has a higher age of consent than elsewhere in the UK (age 17), and is a generally homophobic society. In relation to the latter point, the limited number of gay bars in the Province are generally located in either Belfast and Derry, the two principle cities, gay spaces are regularly picketed by anti-gay protesters, and there are a high number of homophobic attacks. Indeed, Northern Ireland is considered to be amongst the most homophobic parts of the UK.

Both reflecting and countering dominant, cultural ideologies in relation to disability and sexuality is the legislative framework in which service provision is administered. At present, discrimination against disabled people is legislated for by the Disability Discrimination Act (DDA) (1995). Under the DDA, service providers are meant to ensure equal access for disabled people to their buildings and services. The DDA has been described as 'toothless' because there are no enforcement mechanisms and disabled people must challenge unfair discrimination themselves (Oliver \& Barnes, 1998). A National Disability Council, which meet once a week, merely advises the government on its implementation but cannot enforce change. If a disabled person then feels that they are being discriminated against by a family planning clinic, they would have to take a personal case against them, rather than the State using existing legislation to force the clinic to comply.

Access to the built environment and to public space is legislated through the Town and Country Planning Act 1970, Disabled Persons Act 1981, and Part M of the Building Regulations 1987, 1992 (Imrie, 1996). The effectiveness of this legislation is questionable due to the presence of ambiguities and loopholes, and a lack of enforcement. At present, Part M only relates to new public building serving more than 20 people and is based on the concept of 'reasonable provision', which defies legal definition. Imrie (1996) has shown that these pieces of legislation are poorly enforced by local authorities in the UK. For example, he reports that one local authority noted that they use the building regulations sparingly, "we use it about a third of the time, but, of this, less than 25 per cent of the applicants will actually conform to with what we want' 
(Imrie 1996, p.135). The other $75 \%$ were not prosecuted. In other cases, authorities found it very difficult to enforce the regulations, with developers choosing to ignore threats of action which rarely materialised, and $25 \%$ of authorities admitted that they had taken little or no effort to enforce Part M. As such, whilst change is sought, there is much resistance on the ground by both developers and authorities. Old family planning clinics then fall outside of this legislation, and new clinics are under little pressure from the DDA or building legislation to become accessible.

\section{The study}

To provide a preliminary analysis of the levels of access for disabled people to family planning, sex education and sexual health in Northern Ireland we conducted a short questionnaire survey of all family planning clinics in the Province. This questionnaire was not piloted but was based on a similar questionnaire that had successfully been used to survey schools in County Kildare (see Kitchin \& Mulcahy, 1999). All questions were closed so that they could easily be coded by one of the authors, who has very limited use of his arms. The survey consisted of two sections. In the first section, the clinic staff were asked to assess the overall accessibility of the clinic and conduct an access audit of their building. Questions related to parking, entrances, internally design, toilets, signage, specialised equipment (e.g. minicom for deaf people), and treatment rooms. In the second section, the clinic staff were asked about information access and specific services. Questions included asking whether the clinic provided information that was accessible to disabled people (e.g. Braille, audio-tape, signing), how soon that material could be provided; whether the material was specifically produced for disabled people; whether services were provided to people with learning disabilities; whether any staff member was dedicated to disabled clients; whether clinic staff had received disability awareness/equality training and if so how many staff had attended and by whom were they taught. The questionnaire was distributed by post in August 1998 and included a self-addressed envelope. The questionnaire was anonymous to encourage responses without fear of undue publicity. The aim was to assess the state of play, not to make scapegoats of particular clinics. Thirty-four of the 54 questionnaires distributed were returned, a response rate of $63 \%$.

The study was undertaken as part of a larger project assessing how disability research is undertaken. This project consisted of two phases. In the first phase, 35 disabled people were interviewed about their experiences of, and opinions concerning, academic research, how research on disability should be conducted, who should conduct research on disability, and what they would like to be researched (see Kitchin, 2000). In the second phase, the viability of adopting partnership approaches to disability research was explored. The research reported here is the result of one of these partnership projects. The focus of the study was decided by the disabled partner, who was involved in all stages of the research process. Whilst the project reported here is small and exploratory, we nonetheless feel that it serves to highlight the exclusionary landscape of Northern Ireland's family planning clinics and will hopefully stimulate further research on the relationships between disability, sexuality and space.

\section{Results}

The data were analysed by simply comparing and interpreting the significance of levels of provision against an ideal (i.e. full physical, service and informational access). We first discuss the findings in relation to physical access, and then detail findings in relation to information and service access, framing our analysis within the context of cultural ideologies and social justice as outlined above.

\section{Physical access}

Family planning services are usually inaccessible to most disabled men and women (Shakespeare et al., 1996, p. 28).

In contrast to Shakespeare et al.'s observation, 29 out of the 34 clinics which responded considered their premises to be accessible to disabled people. As the data in Table 1 illustrates, however, there is clearly a mismatch between what staff completing the questionnaire determine to be accessible and what proponents of universal design and disabled people themselves consider to be accessible. For family planning clinics to be fully accessible to all disabled people, regardless of impairment, all of the conditions in Table 1 need to be met. No one clinic met all these requirements, and therefore no one clinic is fully accessible. Some may dismiss this is an utopian ideal, but we would counter that all of the conditions in Table 1 are easily implemented, they are encouraged by new legislation, and they are necessary to address issues of dignity and good health in relation to social justice.

Comparatively, wheelchair users and those with impairments that restrict mobility fair quite well. There are, in the majority of cases, accessible parking spaces (although whether these are designated spaces is not known), a ramped/flat entrance, accessible treatment rooms and accessible toilet. The extent to which these 
are really accessible is not known, but we know from experience that what a non-disabled assessor thinks is accessible and what in reality is accessible can differ significantly. For example, if at the top of a ramped entrance a wheelchair user needs to open a double door that opens outwards then they are unlikely to be able to enter without help. Similarly, toilets that are accessible for lightweight wheelchairs are often too small for battery-operated wheelchairs, and corridor access to the toilet can often be restricted. Given the private and sensitive nature of family health, people with mobility impairments should be afforded the dignity to enter and move around a clinic without drawing unwanted attention to themselves.

Whilst the majority of clinics appear to be relatively accessible to disabled people with mobility impairments, between $20-25 \%$ of family planning clinics are not accessible. These clinics exclude disabled clients through their lack of entry and dignified access. A rough estimate suggests that over 10,000 adults aged between 16-64 in Northern Ireland are wheelchair users or have severe mobility problems (approx. 5\% of disabled people, based on PPRU (1992) figures). This means that approx. 2-2500 people with severe mobility impairments have to travel extended distances to visit accessible clinics. This may be further exasperated by a sectarian geography, both in relation to location and travel. In many cases individuals are unwilling to attend places located in spaces 'claimed' by the 'other' side, or to travel through territories occupied by the opposite religion. This is a common problem to all members of the population, but its effects may be aggravated amongst disabled people due to a lack of transport options. A great deal more people with less severe mobility problems may also have to use an alternative clinic (the PPRU report that 139,000 disabled adults in Northern Ireland have locomotion difficulties of some kind, $42 \%$ of which are aged between
16-59). Moreover, few of those clinics needing a lift to get to other floors have one, and few have low counters. In both cases this limits access, restricting and may be denying (depending on circumstances) access to services. The message that this inaccessibility conveys is that disabled people with reduced mobility are not fully-valued clients, and just as importantly it would make working in the clinic difficult for them (only four clinics employed a disabled person).

Whilst wheelchair users might fair relatively well, those people with sensory impairments do not. For example, just under half the clinics had tactile floorways or large print signs suitable for visually impaired people, and only four clinics had minicom systems for use with deaf clients. In only two cases were minicom systems located in treatment rooms. This effectively meant that only two clinics were accessible to deaf people, as the highly personalised nature of family planning and sexual health would preclude discussion in reception areas. Here, the right of dignity, extended to all other clinic users, is being denied to deaf people - a condition that is unlikely to be tolerated by nondisabled clients as it breaks basic social conventions relating to sexual health as a private concern. It is fair to say that access provision for those with sensory impairments is woeful, and the building design and facilities fail to allow independent and dignified use. The extent of this exclusion is placed in context when one considers that there are 88,000 adults with hearing impairments and 57,000 adults with sight impairments living in Northern Ireland [although the vast majority of these are over the age of 60 (77\% hearing, $76 \%$ sight), PPRU, 1992].

\section{Information access}

Accessing information is a major barrier to many disabled people. The information is either not avail-

Table 1

Access audit of family planning clinics in Northern Ireland (\%)

\begin{tabular}{lccc}
\hline & Yes & No & Don't know - N/A - non-response \\
\hline Accessible parking spaces & 91.20 & 8.82 & \\
A ramp and stairs at front entrance & 79.41 & 14.70 & 5.88 \\
Accessible treatment rooms & 76.47 & 20.59 & 2.94 \\
An accessible toilet & 73.53 & 26.47 & \\
Tactile floorways & 47.05 & 38.23 & 14.70 \\
Large print signs & 44.12 & 52.94 & 2.94 \\
Low counters & 26.47 & 55.88 & 17.64 \\
Accessible lifts/stair lifts (if appropriate) & 23.53 & 38.23 & 38.23 \\
An automatic door & 11.76 & 8.82 & 79.41 \\
A Minicom system & 11.76 & 79.41 & 8.82 \\
Accessible treatment rooms (with Minicom) & 5.88 & 55.88 & 38.23 \\
\hline
\end{tabular}


able or is in a format which is inaccessible to the particular needs of the individual: for example, tape or Braille is not readily available, and simple English formats for people with learning difficulties are still a largely new concept. (Shakespeare et al., 1996, p. 18).

The above quote by Shakespeare et al. was amply demonstrated in our study. Only nine of the clinics could provide sex education, family planning and/or sexual health information (e.g. leaflets, booklets, etc.) for those with sensory and developmental/intellectual disability, despite their differing needs and circumstances. This means that in over $70 \%$ of cases, information services provided by clinics were inadequate. Furthermore, none of these clinics could supply this information immediately. In relation, to people with visual impairments four of the clinics could provide information in Braille and three on audio tape but in all cases it could not be supplied in under 24 hours. Signing for deaf people could be provided by eight clinics, three within 24 hours and five over 24 hours. Four of the clinics could provide simplified versions of sexual health/sex education information, but only one within 24 hours. These time delays are particularly significant if we consider temporal services such as the morningafter-pill. A mere eight clinics provided services to people with developmental/intellectual disability (of which there are over 52,000 in the province (PPRU, 1992), and an unknown number with learning disabilities such as dyslexia) and only one clinic indicated that it provided family planning and sexual health information that was specifically targeted towards disabled people. In two cases, clinics indicated that staff members were dedicated to working with disabled clients, and staff at ten clinics had received disability awareness/equality training. In the majority of cases (8), however, training had been to less than $25 \%$ of staff (given that $91 \%$ of clinic employed less than five staff, this meant that only one person per clinic had received training). This paints a picture of a service that is ill-prepared to provide family planning services to disabled people, particularly those with sensory or intellectual disability.

\section{Discussion}

These results, whilst relatively basic in format, are instructive as they indicate to us that disabled people are not expected to be using the services (consultation, treatment, information) that family planning clinics provide. The levels of physical access appear to be partial and inadequate, and clearly fail to meet the general guidelines of the Disability Discrimination Act (DDA)
(1995) that all services and buildings should be accessible to disabled people. Whilst there appears to be relatively high levels of physical access for people with mobility impairments, $25 \%$ of clinics are not accessible. The provision for people with sensory disabilities is woeful. Access to information is severely limited and in the vast majority of cases involves ordering material. Services to disabled people are partial and few clinic employees have received disability awareness/equality training. Disabled people are sexual beings, with the same desires and sexual feelings as everyone, and this needs to be recognised through dignified service provision. We suspect that many clinics would plead that their access, in all senses, is poor because there is limited demand. We would argue that may be demand is poor because disabled people either know provision is weak or feel they cannot avail of services. Moreover, we would argue that this is a social justice and equality issue and, regardless of demand, all clinics should to be inclusive enterprises, offering the same levels of provision across all clients.

To us the lack of family planning facilities, services and information for disabled people reflects dominant cultural ideologies within Northern Ireland (and most other western societies) that expect disabled people to be asexual. Family planning is not an inclusive enterprise and this is reflected in the socio-spatial construction of clinics as landscapes of exclusion. This is not to say that the exclusion of disabled people has been an explicit, deliberate strategy but rather that disabled people have not seriously been considered in the planning and design of family planning clinics; the effectiveness of cultural ideologies has normalised their exclusion to the extent that they are not considered a prime user group. This clearly has to be rectified. This rectification, however, should reflect a desire to recognise and tackle socio-spatial exclusion and should not be a merely cosmetic exercise aimed at fulfilling DDA requirements. To us this means that family planning clinics should develop an inclusive strategy of assessing their access and services through a consultation process with disabled people. Part of this process would necessitate all clinic workers to undergo sexuality and disability awareness training. Such a strategy should be accompanied by a promotional campaign aimed at undermining cultural representations of disabled people as asexual individuals and announcing improved access.

One theme, we have yet to discuss is the levels of access available to gay and lesbian disabled people. It is a subject that we did not cover in the questionnaire. As noted, it is fair to say that Northern Ireland is a generally homophobic place. Although we have no evidence to prove this, these attitudes are likely to be prevalent in health care and social services. This has real implications to the lives of gay, disabled people 
and their access to sex education and sexual health care services. The needs of gay disabled people need to be catered for in the Province's family planning clinics. This means awareness training for staff and promoting clinics as inclusive spaces.

Another theme that needs to be addressed is the process of travelling to the clinics. Making the clinics accessible is of little use if you cannot travel to them. Disabled people as a group have reduced mobility and live in relative poverty which restricts their ability to own and run a car. As a consequence, they are reliant on friends, family, public transport and taxis to travel. Whilst other poor populations might similarly be excluded from attending clinics through their financial circumstances, this is exasperated in Northern Ireland where public transport is largely inaccessible, although this is starting to slowly change with the phased introduction of kneeling buses. Taxis are expensive when living on a limited budget. Thought therefore needs to be given to ways to overcome transport difficulties. A solution, for example, might be for local authorities to provide transport on demand until the public transport system becomes more inclusive.

\section{Conclusion}

Clearly many groups are marginalised within the health sector, with differential access along lines of race and class. However, disabled people are the only group exclusively excluded through an inaccessible environment, as well as income and informational barriers. Family planning clinics in Northern Ireland as currently designed and run are not adequately catering for the needs of disabled clients. Clinics are largely inaccessible in terms of physical access and informational and service provision. They are therefore landscapes of exclusion. We would argue, that such inaccessibility reproduces cultural representations and myths of disabled people as asexual beings and reinforces the idea that disabled people do not need to avail of family planning services. As we have argued throughout the paper, disabled people are sexual beings. Moreover, disabled people do have sexual health issues that extend beyond the general population. The family planning clinics in Northern Ireland need to recognise this and undergo a program of improving their levels of access and the information and services they provide. This should be accompanied by disability awareness training and an examination of the ways in which the clinics reproduce cultural ideologies in relation to disabled people and sexuality. The aim of these programs should be to provide an inclusive and dignified service to all clients, including disabled people regardless of impairment.

\section{References}

Badeau, D. (1995). Illness, disability and sex in aging. Sexuality and Disability, 13(3), 219-237.

Barton, L. (1996). Sociology and disability: Some emerging issues. In L. Barton, Disability and society: Emerging issues and insights (pp. 3-17). Harlow: Longman.

Butler, R. (1999). Double the trouble or twice the fun? Disabled bodies in the gay community. In R. Butler, \& H. Parr, Mind and body spaces (pp. 203-220). London: Routldge.

Butler, R., \& Parr, H. (1999). Mind and body spaces. London: Routedge.

Clements, J., Clare, I., \& Ezelle, L. A. (1995). Real men, real women, real lives? Gender issues in learning disabilities and challenging behaviour. Disability and Society, 10(4), 425-435.

Comfort, A. (1975). Foreword. In T. O. Mooney, T. M. Cole, \& R. A. Chilgren, Sexual Options For Paraplegics And Quadriplegics. Boston: Little, Brown.

Cresswell, T. (1996). Place/out of place: Geography, ideology and transgression. London: UCL Press.

DeLoach, C. P. (1994). Attitudes toward disability: impact on sexual development and forging of intimate relationships. Journal of Applied Rehabilitation Counseling, 25(1), 18-25.

Fegan, L., Rauch, A., \& McCarthy, W. (1993). Sexuality and people with intellectual disability (2nd ed.). Artarmon, NSW, Australia: Maclennan \& Petty.

Ghusn, H. (1995). Sexuality in institutionalised patients. Physical Medicine and Rehabilitation, 9(2), 475-486.

Gleeson, B. (1999). Geographies of disability. London: Routledge.

Hickey, J. (1986). Religion in a divided society. In P. Clancy, S. Drudy, K. Lynch, \& L. O'Dowd, Ireland: $A$ Sociological Profile (pp. 265-282). Dublin: Institute of public Administration.

Hughes, G. (1998). A suitable case for treatment? Constructions of disability. In E. Saraga, Embodying the social: Constructions of difference (pp. 44-90). London: Routledge.

Imrie, R. (1996). Disability and the city: International perspectives. London: Paul Chapman.

Jackson, P. (1989). Maps of meaning. London: Routledge.

Kitchin, R. M. (1998). "Out of place", "knowing one's place": Towards a spatialised theory of disability and social exclusion. Disability and Society, 13(3), 343-356.

Kitchin, R. M. (2000). The researched opinions on research: Disabled people and disability research, Disability and Society 15(1), 25-47.

Kitchin, R. M., Law, R. The socio-spatial construction of disabled-access toilets, Urban Studies (forthcoming).

Kitchin, R. M., \& Mulcahy, F. (1999). Disability, access to education, and future opportunities. Dublin: Combat Poverty Agency.

Lamb, B., \& Layzell, S. (1994). Disabled in Britain: A world apart. London: SCOPE.

McAllen, L. C., \& Ditillo, D. (1994). Addressing the needs of lesbian and gay clients with disabilities. Journal of Applied Rehabilitation Counseling, 25(1), 26-35.

McCabe, M. P., Cummins, R. A., \& Reid, S. B. (1994). An 
empirical study of the sexual abuse of people with intellectual disability. Sexuality and Disability, 12(4), 297-306.

Monga, T. N., \& Lefebrve, K. A. (1995). Sexuality: An overview. Physical Medicine and Rehabilitation, 9(2), 299-311.

Muccigrosso, L. (1991). Sexual abuse prevention strategies and programs for persons with developmental disabilities. Sexuality and Disability, 9, 261-272.

Napolitano, S. (1995). Mobility impairment. In G. Hales, Beyond disability: Towards an enabling environment (pp. 30-35). London: Sage.

Nelson, M. R. (1995). Sexuality in childhood disability. Physical Medicine and Rehabilitation, 9(2), 451-462.

Nosek, M. (1995). Sexual abuse of women with physical disabilities. Physical Medicine and Rehabilitation, 9(2), 487502.

Oliver, M. (1996). Understanding disability: From theory to practice. Basingstoke: MacMillan.

Oliver, M., \& Barnes, C. (1998). Disabled People and Social Policy. Harlow: Longman.

O'Toole, C. J., \& Bregante, J. L. (1992). Lesbians with disabilities. Sexuality and Disability, 10(3), 163-172.

Park, D. C., \& Radford, J. (1999). Rhetoric and place in the 'mental deficiency' asylum. In R. Butler, \& H. Parr, Mind and body spaces (pp. 70-97). London: Routldge.

PPRU (1992). Policy Planning Research Unit. The prevalence of disability among adults in Northern Ireland. PPRU Surveys of Disability Report 1, Belfast.

Pitzele, S. (1995). Chronic illness, disability and sexuality in people older than fifty. Sexuality and Disability, 13(4), 309-325.
Rousso, H. (1982). Special considerations in counseling clients with cerebral palsy. Sexuality and Disability, 5(2), 78-88.

Schlesinger, L. (1996). Chronic pain, intimacy, and sexuality: A qualitative study of women who live with pain. The Journal of Sex Research, 33, 219-256.

Shakespeare, T., Gillespie-Sells, K., \& Davies, D. (1996). Untold desires: The sexual politics of disability. London: Cassell.

Sibley, D. (1995). Geographies of exclusion: Society and difference in the west. London: Routledge.

Szollos, A. A., \& McCabe, M. P. (1995). The sexuality of people with mild intellectual disability: perceptions of clients and caregivers. Australia and New Zealand Journal of Developmental Disabilities, 20(3), 205-222.

Tan, G., \& Bostick, R. (1995). Sexual dysfunction and disability: Psychosocial determinants and interventions. Physical Medicine and Rehabilitation, 9(2), 539-554.

Tilley, C. M. (1996). Sexuality in women with physical disabilities: A social justice or health issue? Sexuality and Disability, 14, 139-151.

Watson-Armstrong, L. A., O'Rourke, B., \& Schatzlein, J. (1994). Sexual abuse and persons with disabilities: a call for awareness. Journal of Applied Rehabilitation Counseling, 25(1), 36-42.

Waxman, B. F., \& Finger, A. (1991). The politics of sexuality, reproduction and disability. Sexuality Update, National Task Force on Sexuality and Disability, 4(1), 1-3.

Wolfe, P. S. (1997). The influence of personal values on sexuality and disability. Sexuality and Disability, 15(2), 69-90. 